\title{
ERRATUM
}

\section{Erratum to: Desert riparian forest colonization in the lower reaches of Tarim River based on remote sensing analysis}

\author{
Guilin Liu • Alishir Kurban · Hanming Duan • \\ Umut Halik · Abdimijit Ablekim • Luocheng Zhang
}

Published online: 6 December 2013

(c) Springer-Verlag Berlin Heidelberg 2013

\section{Erratum to: Environ Earth Sci}

\section{DOI 10.1007/s12665-013-2850-9}

The authors would like to correct errors in the original publication as detailed below.

The correct version of the author lists is given here:

Guilin Liu · Alishir Kurban · Hanming Duan ·

Umut Halik · Abdimijit Ablekim · Luocheng Zhang

The online version of the original article can be found under doi:10.1007/s12665-013-2850-9.

G. Liu · A. Kurban $(\square)$

Xinjiang Institute of Ecology and Geography,

Chinese Academy of Sciences, Ürümqi 830011, China

e-mail: alishir@ms.xjb.ac.cn

G. Liu $\cdot$ L. Zhang

Nanjing Institute of Geography and Limnology,

Chinese Academy of Sciences, Nanjing 210008, China

G. Liu

University of Chinese Academy of Sciences,

Beijing 100049, China

H. Duan

College of Land and Resource, China West Normal University,

Nanchong 637002, China

U. Halik

Xinjiang Key Laboratory of Oasis Ecology,

College of Resource and Environment Sciences,

Xinjiang University, Ürümqi 830046, China

A. Ablekim

College of Geographic Science and Tourism,

Xinjiang Normal University, Ürümqi 830054, China 